\title{
The ideal health minister
}

\section{J Dwyer}

\section{Has an ability to reinvent themselves}

of n November 2001, Dr Michael Wooldridge, Australia's health minister of nearly six years, retired from politics at the age of 45. In retiring early, Dr Wooldridge fulfilled his own longstanding prediction that the health portfolio would be his political graveyard, and in this he shared the fate of most Australian health ministers over the past 30 years. It seems that, in Australia, there is little chance of life in politics after health and the ideal health minister needs the capacity for a second or third career as well as the ability to live with political risk.

Yet the health portfolio is a senior cabinet position, and health policy is a matter over which government can be won and lost. Our tax based system of universal access to medical, hospital and subsidised pharmaceutical services, supplemented through private insurance and private health services, ensures that health is an electoral issue, and never long out of the media and public debate. But not, apparently, a training post for future party leaders or prime ministers.

Health remains a deeply contested ground, and a test of strength for the minister. One of the key testsregardless of the political colour of the government-is the minister's ability to retain control over health policy against the depredations of the central agencies, the departments of prime minister, treasury and finance, which are the natural enemies of this largest of the "spending portfolios". The second key test is the ability to do more than this-to move beyond health financing and into more substantive areas.

The task of the health ministers is also complicated by a jurisdictional problem. Australia has a population of less than 20 million people, and nine ministers of health-one federal and eight for the States and Territories. Responsibilities for all aspects of the health portfoliopolicy, public health, and health careare divided and overlapping across the two levels of government. We have no shortage of ministerial attention, and a large infrastructure of coordinating mechanisms has grown up to enable national action on key policy areas-like research, food and drug policy, aboriginal health and public health.

In this setting, the ideal health minister needs a talent for coalition building towards a coherent policy agenda. Just understanding the dynamics and contradictions can take years for a novice, so

\section{The ideal minister of (public) health}

\section{N Pearce}

\section{Should be in a minister of public health, not a minister of health}

am going to answer this question indirectly, for two reasons. Firstly, because I don't think it is possible to make a prescription for the ideal minister of health as so much depends on personal skills and the current circumstances (apart from the need for her/him to be electable!). Some of the best New Zealand ministers of health have had no obvious qualifications for the job, whereas other ministers with more relevant backgrounds (in medicine or nursing) have been less successful. The second, and more important, reason is that I don't think the question can be answered without first discussing what the role of the health services would ideally be.

The fundamental problem for ministers of health, as well as public health researchers and policy makers, is that the health services at most have a minor influence on the health of a population. What the ministers of finance, systems thinking is needed, and a background in the health professions is an advantage.

But when I think about the dozen or so health ministers (federal and state) with whom I have worked and sometimes struggled, it seems to me that the keys for success are a combination of commitment to policy goals that stand above the dusty arena of politics, and the strength to maintain control of the policy agenda.

Dr Neal Blewett (health minister from 1983 to 1990 and one of the few not to fade from the front bench immediately) may well be judged the most significant achiever in the portfolio over the past 30 years. Dr Blewett will be remembered for his success in reinstating universal access to health care through Medicare, and for his leadership of Australia's prompt and successful strategies in response to the HIV/AIDS epidemic.

Both of these initiatives have survived and now enjoy popular support (although Medicare remains under constant challenge from conservative governments that profess commitment while they chip away at the policy foundations). But at the time, they were politically courageous, socially progressive, and required the ability to extract new money for health care. Ideal characteristics for a health minister.

J Epidemiol Community Health 2002;56:888

Author's affiliations

J Dwyer, Health Services Management, La Trobe University, Victoria 3086, Australia and Board Chair, Australian Resource Centre for Hospital Innovations

Correspondence to: Professor J Dwyer; judith.dwyer@latrobe.edu.au

employment, social welfare, education, housing, labour, etc, do will inevitably have much greater influence on population health than what the minister of health does. The traditional public health approach to this problem has been to attempt to "turn the health services into public health services" and to attempt to persuade the health services to become interested in these broader issues. This is not surprising; given that most public health workers have initially trained in clinical medicine, and have continued to work within the health services, albeit in a different role after their conversion to the public health approach that focuses on prevention in populations rather than treatment of individuals.

However, I think it is time to reconsider this approach. It has rarely if ever worked, for the obvious reason that when public health attempts to influence the health services it is a very small tail trying to wag a very large dog, which wants to run in another direction. 
People working in the health services like to do what they were trained for, and generally do very well-that is, treating illness in individuals, and they usually have neither the time, the ability, or the resources, to deal with larger issues of prevention in populations. Their administrators also usually have more urgent priorities. As a result of this well meaning but naive attempt to transform the health services, public health has gone backwards internationally over the past two decades. It has continually lost out to the "conventional" health services in battles for resources, and it has had little influence on the important public health problems at the population level.

Perhaps it is time to seriously consider another approach-that is, establishing a ministry of public health. Public health services for individuals (for example, immunisation) would continue to be delivered through the ministry of health, and we would continue to attempt to transform the health services towards public health as much as this is possible. However, the ministry of public health would tackle the real public health issues at the population level. It would solely have a monitoring and advocacy role, not only with regards to routine monitoring of death rates, the population burden of disease, etc, but also with regards to monitoring and influencing the work of the other government departments and ministries (including the ministry of health). One way (but not the only way) to do this is through Health Impact Assessments of the possible health effects of different policy options proposed by the other government ministries and departments. Health Impact Assessment is not straightforward, but such quantitative estimates, however debatable and tentative, can play a key part in ensuring that health concerns are taken into account in economic and social policy.
If this approach were adopted, then the minister of health and the minister of public health would both clearly play an important part in government, but would require different skills. The first would need the skills required to run the health services (including public health services at the individual level). The second would require the skills needed to play a monitoring and advocacy part to ensure that the likely population health effects were taken into account in the work of all other government departments and ministries, including the ministry of health.

$J$ Epidemiol Community Health 2002;56:888-889

Author's affiliations

N Pearce, Centre for Public Health Research, Massey University Wellington Campus, Private Box 756 Wellington, New Zealand

Correspondence to: Professor $N$ Pearce; n.e.pearce@massey.ac.nz

\section{My ideal minister of health}

\section{K McPherson}

\section{Will have the guts to maximise health}

T he perfect minister of health would have to understand about healthnot so much the desperate manifestations of ill health. Such a person would have to understand that a large proportion of chronic illness-at least until age 75 or thereabouts is essentially avoidable. Then health policy might change so that in the longer run the population served would be healthier and the expenditure of medical services proportionately less. That should be their objective.

But all that requires courage and a commitment to experiment sensibly and efficiently. Policy would incorporate, as matter of course, rigorous evaluation components and would get to serious grips with changing circumstances and opportunities to enable real choice for people that matter. The minister would involve the public in a serious public health endeavour that eschewed all coercion, all patronising, and all nannying. The objective would become a national enthusiasm - that would be different and special among different communities. Nobody wants to be ill but few have real opportunities for doing much about impending disease 40 years on. But this is a social and political choice for government to facilitate under a national initiative. Immunisation and vaccination are well accepted and clearly require support, both intellectual and actual, to enable them to work.

Why then are highly cardiotoxic diets (in the longer run) widely marketed and the safer and (in many people's view) better options more expensive, less available, and culturally alien. And they taste worse too. Why do governments with a minister for health allow schools to sell their sports fields, procrastinate about tobacco advertising, take no lead on dietary change, and so on. Mainly because they don't understand that health is, in the main, not determined by health services. And also because they relish the power of controlling an important and vital public institution.

Get a strong minister who understands the basics of the biology of health-most chronic diseases have 50 year gestations and hence attitudes and options available to youngsters are worth thinking about. Many have common causes and we need to know about their relative potencies. So public money needs to be spent on finding out. This is not to get stern or impose restrictions but to invest in making healthy options more attractive-indeed sexier.

All this needs a new and credible scientific infrastructure to ensure that a competent workforce is well consolidated in daily life. Odd that we have lawyers, doctors, engineers, teachers, and whatever else and not even a word, never mind a coherent function, for public healthists. Public health really is quite as important as the rest, surely?

So we need a minister for public health in the highest echelons of government power whose remit is maximising health and hence minimising health services, to deal much more effectively with unavoidable illness and the needs of the elderly population. At the moment we are mostly getting the worst of both worlds - too much avoidable illness and massively inadequate health services. It is time to break out of that vicious cycle in all of our interests.

J Epidemiol Community Health 2002;56:889

\section{Author's affiliations}

Klim McPherson, Department of Social

Medicine, University of Bristol, UK

Correspondence to: Professor K McPherson;

Klim.McPherson@bristol.ac.uk 


\section{An ideal minister of health}

\section{La Vecchia, S Garattini}

\section{Should work across government and be a collaborator}

a n developed countries, health systems are complex structures that may run even in the absence of a minister of health, and at least in Italy the idea of abolishing the ministry of health and de-centralising its powers has long been considered.

A key issue is, therefore, what can an ideal minister of health add, and what skills are required. To successfully finalise his activities, a minister of health should have a deep knowledge of the way the ministry-and the government at large-are working. Otherwise, the minister may will be overwhelmed by bureaucrats, and even the best initiatives will never be approved.

The minister must be able to communicate the value and importance of health related issues, in order to provide adequate support to them. The minister must also be able to communicate priorities in health, giving information on quantitative relevance of various issues on the health of the population. For instance, a minister of health should have adequate skills and prestige to explain in quantitative terms the health consequences of tobacco, BSE, and electromagnetic fields, ${ }^{1}$ and give consequently rational priorities for interventions.
The minister of health is frequently seen as a technical job, and-at least in Italy - most health ministers over the past decade have been doctors. Not surprisingly, however, their impact even on important health related issues has been limited. Thus, none of them was able to implement a modern tobacco legislation despite several attempts and substantial support from public opinion. ${ }^{2}{ }^{3}$

Whatever the background of the ideal minister, he must be able to identify and select competent collaborators from various disciplines, including medical, social sciences, economics and ethics, and to organise multidisciplinary working groups. A minister should, in any case, be able to identify groups of competent and independent advisors to evaluate and review official acts and their implications. The minister should not havepresent or past-conflicts of interest, including links with the pharmaceutical industry, private hospitals, or other health related economic activities. The minister must also have adequate time and competence to follow the organisation and efficiency of services provided by the ministry.

A minister should be able to organise budget and resource allocation-if required. Political attitudes will also be required to assess and balance various health related interests, including those of doctors and other health professionals, of hospitals and other public and private service providers, of the drug industry and regulatory agencies.

Throughout this editorial, we have not tackled the issues of ethnic background and gender, as they are neutral, and only for the sake of simplicity we have used "he" instead of "she" in the text. Within the relatively small political differences seen in most western Europe countries, even the political orientation is probably not vital. Left wing politicians tend to be more open to social and hence equity related issues, but health is such a basic requirement that most right wing politicians would not be willing to support or increase inequalities in health.

\section{ACKNOWLEDGEMENTS}

This work was conducted with the contribution of the Italian Association for Cancer Research. The authors thank Mrs M Paola Bonifacino for editorial assistance.

J Epidemiol Community Health 2002;56:890

\section{Authors' affiliations}

C La Vecchia, S Garattini, Istituto di Ricerche Farmacologiche "Mario Negri", Milan, Italy C La Vecchia, Istituto di Statistica Medica e Biometria, Università degli Studi di Milano, Milan, Italy

Correspondence to: $\operatorname{Dr} C$ La Vecchia; bonifacino@marionsgri.it

\section{REFERENCES}

1 La Vecchia C, Anelli M, Zuccato E, et al. Perceived risk of cancer in population samples from 5 European countries. Int $J$ Cancer 2000;86:747-8

2 La Vecchia C, Garattini S. Attitudes to legislation on restriction of smoking. Lancet 1987;i:1310.

3 La Vecchia C, Garattini S, Colombo P, et al. Attitudes towards smoking regulation in Italy. Lancet $2001 ; 358: 245$.

\section{The ideal minister of health}

\section{L Barreto}

\section{Should mainstream public health}

A ter more than two decades of dictatorial government, Brazil began a new democratic era in 1985. The new constitution, elaborated and promulgated in 1988, stated that "health is an universal right and a State obligation guaranteed by social and economic policies aimed at reducing the risk of diseases and other ill-related events and by universal and egualitarian access to a health care system oriented towards health promotion, protection and recovery", (Federal Constitution of Brazil, Article 196, 1988). Following this, Article 3 of Law 8080 enacted in 1990, stated that " food, housing, sanitation, the environment, work, income, education, transportation, leisure and the access to essential goods and services are all important health determinants; therefore, health status reflects the social and economic organization of the country".

These legal documents incorporated the rationale used by national and international public health movements to understand and elaborate global strategies for achieving good standards of health. On these grounds, we expected that the ministry of health would have defined effective policies to improve the health of Brazilians. Unfortunately, the ministry of health has failed to assume its constitutional responsibility. More than a decade after the constitution of 1988, limited advancements in health services organisation and healthcare delivery have been achieved so far; health standards in Brazil are still low for large segments of our population, and curative oriented programmes are still given priority over disease prevention and health promotion. 
Considering that this pattern of health service organisation occurs in most nations we must ask-is this an acceptable standard, or a generalised mistake?

In my opinion, at least two major issues need to be tackled. Firstly, at the political level, health policies are included as an isolated sector of the social agenda, which, by its turn, is considered secondary to the economic agenda. From this perspective, the health sector has its focus limited to the effects rather than the causes of diseases. In addition, we must consider the tendency to individualise or privatise health risks. ${ }^{12}$ This tendency is reinforced by the overemphasis of individual based risk factors identified by epidemiological studies, and leads to a health system that targets individuals rather than populations. $^{34}$

Both of these issues are related to the mainstream "biomedical" understanding of health, which gives more relevance to diseases than to their causes. Shifting the emphasis to the causes of disease requires the promotion of broad social and economic policies that seek to improve all aspects of life. As a result, the development of guidelines for a ministry of health in consonance with the Brazilian Constitution and laws depends on: (1) reorganisation of the State administration, with health as a central and strategic goal of the social and economic agendas; and (2) prioritisation of epidemiological research and practice that elucidates the intricate and complex effects of biological, environmental, and social factors on health, and actions that target populations rather than individuals. We epidemiologists need to share the view that the important part of the risk factors in the contemporary world are not "natural" but generated by actions of human beings, not as individuals but as members of societies. As consequence, these risk factors must be modified by societal actions. ${ }^{5}$

$J$ Epidemiol Community Health 2002;56:890-891

\section{Author's affiliations}

M L Barreto, Instituto de Saúde Coletiva Universidade Federal da Bahia, Rua Padre Feijó, 29, Salvador-Bahia, 40, $110-170$ Brazil

Correspondence to $\operatorname{Dr} M$ L Barreto;

mauricio@ufba.br

\section{REFERENCES}

1 Rockhill B. The privatization of risk. Am J Public Health 2001;91:365-8.

2 Wing S. Limits od epidemiology. Med Global Survival 1994;1:74-86.

3 Rose G. Sick individuals and sick population. Int J Epidemiol 1985; 14:32-8.

4 Barreto ML, Alves PC. O coletivo versus o individual em epidemiologia: contradição ou síntese. In: Costa JFFL, Souza RP, eds. Qualidade de Vida: Compromisso Histórico da Epidemiologia. Belo Horizonte: COOPMED/ABRASCO, 1994:129-36.

5 Breilh J. Epidemiologia: Economia, Medicina y Política. Mexico: Fontamara, 1989.
Health minister

\section{A minister of health}

\section{J Breilh}

\section{Should challenge trendy global corporatism}

$\mathrm{R}$ egrettably it is in the so called "democracies" of the North and South where globalisation has become the scenario for market fundamentalism and an absurd race to the bottom, in which economical and social rights have been demolished and countries compete for, what will in fact, see the situation of first being the worst in human terms. The neoliberal state in those democracies has installed a process of social and cultural counter reform that deny equity in principle and in fact, consecrating a systematic violation of the codes that guarantee standards of life and dignity, which are the basis for health. Our societies have institutionalised a combination of subtle and cruel mechanisms to deprive people of means to develop their own identity and the best in their culture, turning, as such into oppressive and violent societies, with apparently democratic but essentially authoritarian governments. Cultural institutions are deteriorating, universities and educational centres are being converted in docile sources of functionalist formulas.

Under such conditions we have to mobilise all our efforts to recuperate the human and scientific nature of medicine and public health and to deconstruct the hegemonic models for research, teaching, and practice; models that conceal their lack of solidarity, imagination, and dreams, behind the shield of a variety of functionalist technologies.

The construction of a democratic process of health reform does not depend mainly on personal leadership, nor on the profile of a person that is placed at the head of a power structure, that is because good intentions and personal talent cannot revert the policies and strategies of that power structure. The reason why, with alarming repetitiveness, people with scarce talent, academic proficiency, and ethical links to their people reach leading posts of public offices, is not because the adequate profiles remain unknown, in contrast, the recruitment process of public officers and ministers, depends on political strategies that assess compliance of those officers to hegemonic policies and their willingness to accept the game rules of such power structure.

It is much more important to emphasise collective leadership and social organisation as means of health reform. The main problem resides in how to construct a parliamentary and participative process, through strategic planning, collective health monitoring, and social control of health practice and programmes. Only this way will it be possible to build up a health system based on equity (social, ethnical, and gender wise), solidarity, and collective quality monitoring. Voices from all over the world express the public demand for dismantlement of neoliberal policies, geared towards a lucrative, mercantile, and inequitable scheme of health distribution that have widened social, gender, and ethnical inequity. We must rescue our institutional expertise and the talent of health professionals for building a health system that reflects democracy and good quality of life in itself and holds straightforward human rights advocacy as fundamentals of prevention and health care.

It is time to revert that regressive "modernisation" and deconstruct the rigid and Cartesian perspective that has dominated the practical and theoretical health scenarios of care, prevention, teaching, and research, submerging us in a positivistic and techno-bureaucratic vision of science and technology; a vision that is now proposing that we erase all human meaning from health practice and convert it into an expensive merchandise, inaccessible by the vast majority of the developing world and even of the developed world.

Only under collective, well informed, leadership and only by organisational strengthening of the people and of their technical and academic allies, will we be able to implement socially equitable, high quality and universal health resources; and it is only towards that purpose, and inscribed under that logic that it makes sense to inquire about 
individual leader profiles; not only of health ministers, but of all health officers and leaders. Our experience is saturated by negative examples of notorious personalities-even some of democratic and well educated backgrounds - that once inserted in that power structure

end up being more "holier than the Pope", and end up using an alternative progressive lexicon, supposedly counterhegemonic, to disguise their truly neoliberal misdoings.

$J$ Epidemiol Community Health

2002;56:891-892
Health minister

\section{The ideal minister of health}

\section{S K Kapoor}

\section{Background and outlook matters, not necessarily medical qualifications}

deals exist only in fiction but shape our thinking. Over the years, only a few health ministers in India have managed to leave a lasting impression. In my personal opinion, the two best were Rajkumari Amrit Kaur and Karan Singh. Both had a royal lineage and were steeped in Indian values and part of the freedom struggle. While Rajkumari provided the initial impetus and dynamism to the ministry immediately after independence, Dr Singh came at a time when health was declining in importance in the government. Both of them were philosophical (Dr Singh has a doctorate) and had a very broad vision and looked at health in its entirety. India also had doctors as the health minister, though they did not do as well. Our experience has been that doctors as health ministers tend to have a narrow interpretation of health and look more into curative aspects than public health aspects. While in general, it is believed and is probably true that, women have more empathy for this kind of work, our experience is that this empathy does not get translated into any concrete action at policy or implementation level. Having a real grass root experience, preferably with a rural background, has its advantages. This gives you a sense of equity and a real close look at the problems that you are trying to solve. However, you should be careful that, while you get a ringside view of the things, we need a bird's eye view for policy matters so that we get the right perspective.

In India, the health ministry currently gets a very low priority. On many occasions there is not a full fledged cabinet minister but only a minister of state. Partly the reason for this is that health is in a concurrent list, which means that state governments have an equal part to play. Many states are larger than most countries in the world in terms of population. In states, the priority for health is even less important. In this era of decentralisation and restructuring, there

\section{Author's affiliations}

J Breilh, Health Research and Advisory Centre and Development Research Centre, Quito, Ecuador

Correspondence to: Dr J Breilh; jbreilh@ceas.med.ec was even a thought as to whether a health ministry is needed at all at the central level. Only the fact that many of the disease control programmes are centrally funded and the state governments are not inclined to pick up the bills, has ensured its continuation. Undoubtedly there is a need to bring health into the centre of focus. We therefore need people who have a high public profile and are media savvy. However, it is also true that such a high profile politician is unlikely to be happy with the health ministry and might consider it as a "let down". Unlike in the past, we now have young urban, sophisticated professionals entering politics. This augurs well for politics in general but whether this will usher professionalism in the health ministry is to be seen.

In conclusion, there is no doubt that we need to clean the Augean stables of the health ministry. There is nothing like a woman, preferably a dominating one (a la Brundtland perhaps!) to wield a broomstick for cleaning the corridors of the health ministry. We need to jolt the bureaucrats and technocrats of the health ministry into action.

J Epidemiol Community Health 2002;56:892

\section{Author's affiliations}

S K Kapoor, Comprehensive Rural Health Services Project, All India Insititute of Medical Sciences, New Delhi 110029 , India

Correspondence to: Dr S K Kapoor; crhspaiims@sancharnet.in
Japan is now in transition to fundamental reform of its administration system. It is moving a large, rigid government bureaucracy to a system that favours deregulation, transparency, and smaller government. In this context, the work of Japan's ministry of health is expected to change from a vertical approach to a comprehensive one that can act promptly and incorporate intersectoral collaboration. However, this change has not been progressing quickly enough.

Japan's rigid bureaucratic system led health development through the entire country in the past through vaccination programmes, school health programmes, a public health insurance system, and so 
on. The compulsory and collective measures were effective. The system was also able to accumulate the experiences of professionals and create specialists who were experts in narrow fields. However, because of changes in society the old way doesn't work anymore. In the past 10 years, there have been several important public health scandals: HIV infected blood products were allowed to be used, a severe lack of collaboration between the ministry of health and the ministry of agriculture helped increased contamination of BSE prions, and sufferers of Hansen's disease had to wait far too long to be rehabilitated into society. The list of scandals continues. Ministry structure has basically continued unchanged even though superficial restructuring was carried out

The ideal minister should be skilled at politics, but should come into the position from outside the ministry of health. This means that the minister could come from, for instance, the upper levels of an university, a large, transnational NGO, a large corporation, or a large organisation. A degree in medicine is not always needed. The minister does not need to be well known before assuming the position, either.

Japan's citizens would now like to participate in health issues more subjectively. They want prompt and open measures against new health problems. They want leadership that has interministerial collaboration. These positive potentialities have not yet been embraced by the ministry. An outstanding minister would be needed to make two large changes at the same time: change the ministry's conventional structure and invite citizens into health administration in their communities. The ideal minister needs to be a very good listener and pay attention to outside academics, and the public. The minister needs to have the power to install the bureau chiefs of the ministry of health. In short, the ideal minister has to have a rare mixture of idealism and realism.

In addition to the above, there is one essential prerequisite for the ideal minister. $\mathrm{S} /$ he needs to be a long time reader of this journal!

$J$ Epidemiol Community Health 2002;56:892-893

\section{Author's affiliations}

T Takano, Health Promotion/International Health, Division of Public Health, Graduate School of Tokyo Medical and Dental University, Yushima 1-5-45 Bunkyo-ku, Tokyo $113-8519$, Japan

Correspondence to: Professor T Takano: takano.hlth@tmd.ac.jp

\section{Wanted: one ideal Canadian federal health minister (who walks on water)}

\section{R Labonte, A Williams, L Biggs}

Y ou are excited by the challenge of Canada's interesting constitutional division of powers, in which the federal government is expected to contribute to health systems largely under the control of provincial governments, most of which will constitutionally disagree with anything you propose except the promise of more money.

You are resistant to media attacks that continually point to the declining federal contribution to health systems, and are able to convince your finance and international trade colleagues in the cabinet of the wisdom of progressive taxation to increase public funding for effective health services. Your conviction in evidence based policy making (rather than policy based evidence making) allows you to confront head on the economic interests behind the push for widespread privatisation of health (and education, and social services, and anything else "inefficiently public"), with convincing references attached.

You are inspirational in your communication to the nation's diverse publics that not only is progressive taxation a fair way to finance public goods; it is also good for our publics' health. Your sophisticated knowledge of population health research allows you to acknowledge that income inequality remains a contested health determinant. It also allows you to point out convincingly that public investments allowing universal access to education, shelter, good nutrition, and environmentally safe and playfully stimulating homes, neighbourhoods and communities are good for our health, our economy, and our planetary survival.

You both think and act globally, knowing that a resistant disease in Africa can hop to Canada in less than a day, and that escalating disease coupled with widening inequalities and weakened public services are the greatest drivers to regional conflict, hence global insecurity. You are a tireless advocate in public and in camera for trade agreements that promote health and protect the environment, and for Official Development Assistance levels that do not make a mockery of the $0.7 \%$ of GNP commitment.

You fully grasp the tenets of health promotion, whereby health systems, even as they provide downstream cure and care, also participate in upstream prevention and protection. You support efforts to cull good practices (never letting the tyranny of the "best" get in the way of the simply "good") in health education, community development, and the health system's "watchdog" role as advocate for social and physical environments-in the home, the community, the workplace-that enhance health and form a foundation of our social capital.

You are a weaver of "joined up" governance, knowing that the publics' health requires collaborative policy making from many more ministries than your own; involves many other government levels; and needs input from a messy range of stakeholder groups in civil society, where business interests and public interests are not always the same. You know how to put problems, rather than your own ministry, in the centre of intersectoral collaboration, and understand that converting others to your discourse is neither necessary for, nor even useful in, effective collaboration.

You are an experienced activist in the politics of the excluded, and not simply the politics of the party. You have spent time with our Inuit, First Nations, and aboriginal communities. You recognise the diversity of women's health needs. You have a deep empathy for minority ethnic groups, regional variations, and linguistic differences. You have heard the Maritime lament of fishless oceans. You are fluent in both official languages. You respect the populous weight of our industrial centre, understand its urgent drive towards the knowledge economy, and recognise the need to ensure the 
dignity of those caught in the transition's wake. You respect rural life, its deeply valued traditions and commitment to community. You share the fears of drought, climate change, and corporatisation with our Prairie farmers. You wrest over the dilemmas of resource based economies devastating our environment (its health, our health), or reeling from past devastations of depletion and exhaustion, and ponder the challenges of the new global economies.
Finally, your years in community work are complemented by your years in tertiary learning, providing you with a healthy respect for the spectrum of health research required for better political and public decision making, and to help build our nation's human capital.

(Ability to leap tall buildings in a single bound desirable but not required.)

$J$ Epidemiol Community Health 2002;56:893-894

\section{Authors' affiliations}

R Labonte, Saskatchewan Population Health and Evaluation Research Unit and Community Health and Epidemiology, University of

Saskatchewan, Canada

A Williams, Research Faculty, Saskatchewan Population Health and Evaluation Research Unit and Geography, University of Saskatchewan L Biggs, Women's and Gender Studies,

University of Saskatchewan

Correspondence: Professor R Labonte, SPHERU, Health Sciences Building, University of Saskatchewan, 107 Wiggins Road, Saskatoon, SK, Canada S7N 5E5;

ronald.labonte@usask.ca

\section{The ideal minister of health}

\section{S Oreskovic}

\section{Should be performed and managed on stewardship, loyalty, authority, and efficiency}

in

$\mathrm{n}$ his effort to escape from the individualising and particularising approach of German historicism, Max Weber developed a key conceptual tool, the notion of the ideal type. An ideal type is an analytical construct that serves the investigator as a measuring rod to ascertain similarities as well as deviations in concrete cases. What are the similarities and deviations from "ideal type of health minister" among ministers of health around the globe? And what would be an ideal minister of health in the 21 st century? Perhaps the minister should be validated against the following objectives: stewardship, loyalty, authority, efficiency.

The question is to whom the "ideal" minister of health should direct his stewardship? "Stewardship is about vision, intelligence, and influence" is probably the most strategic sentence of the WHO World Health Report 2000. ${ }^{2}$ If the minister of health would like to act as a "good steward" responsive to the citizens and their needs she should concentrate on three substantial health issues: overuse, underuse, and misuse of health services. In many countries, both developed and developing interventions that are of little value are commonly overused; care that is effective is commonly underused; and care that is of unproved value is frequently misused. ${ }^{3}$ More diagnosis creates the potential for labelling and detection of pseudodisease-disease that would never become apparent to patients during their lifetime without testing. Survival rates after acute conditions like acute myocardial infarction (heart attacks), stroke, and gastrointestinal bleeding were not correlated with more intensive healthcare spending. ${ }^{45}$ Overuse of antibiotics increases the chance that bacteria can breed new strains able to survive the drug onslaught, rendering it ineffective. Paradoxically $30 \%$ of the world lacks access to essential antibiotics like penicillin or chloramphenicol, but at the same time, in the United States and Canada, 50\% of outpatient prescriptions for antibiotics are unnecessary. ${ }^{6}$ Underuse refers to the failure to apply, when indicated, treatments that have been shown to be effective in medical care. In developing countries underuse because of poor access to services is overwhelmingly the most severe problem, followed by misuse. The South African HIV story is good example of divided loyalty. The minister has to decide where to direct his loyalty and accountability: international regulations, financial interest of the national treasury, pharmaceutical industry, or health needs of the citizens. Approximately 200 HIV positive babies are born each day in South Africa, and use of nevirapine can reduce mother to child transmissions by half. Some doctors illegally prescribe nevirapine to pregnant women. Finally, the Treatment Access Campaign (TAC) won a lawsuit against the South African minister of health, Manto Tshabalala-Msimang, and nine provincial health ministers, forcing the government to provide nevirapine through the public health sector for the prevention of mother to child transmission of HIV.

Facing both political and professional challenges the minister of health should not try to act as a standard charismatic authority typical for the other sectors of state policy. Neither should the minister turn to belief in the sanctity of tradition, of "the eternal yesterday", which rests on the appeal of the medical profession that claim allegiance because of their extraordinary virtuosity resulting in internists, surgeons, radiologists, psychiatrist, and microbiologists' minds at the post of health ministers without strong public health action. "My successor will be a pathologist" pointed out by the Croatian minister of health, Andro Vlahušić. Authority of the health minister should not arise from such "professional" background but rather from public health advocacy and responsiveness to the citizens health needs. She should apply theory of modern public administration assuming that the authority to order certain matters by decree does not entitle the ministers to regulate the matter by commands having the reputation of the most bureaucratic and least effectively managed institutions in the public sector. ${ }^{8}$ Effective and efficient health policy should be guided by priorities, objectives, processes, and outcomes. This stands in extreme contrast with the regulation of all relations through individual privileges and bestowals of favour*, absolutely dominant in a political and professional health patrimonialism. ${ }^{9}$

$J$ Epidemiol Community Health 2002;56:894-895

${ }^{*}$ Australian former health minister Dr Michael Wooldridge last year approved a $\$ 5$ million grant to the Royal College of GPs for a building to help co-locate several doctors' groups. That same organisation now employs Dr Wooldridge as a consultant. Prime minister John Howard is now ordering an investigation and flagging the possibility that he might pull the plug on the contract. Dr Miodrag Kovac Federal Secretary for Labour, Health and Social Welfare of FR Yugoslavia committed suicide in April in Madrid because of accusation of corruption in decision making about the purchase of medical equipment. 


\section{Author's affiliations}

S Oreskovic, Andrija Stampar School of Public Health, Rockefellerova 4, 10000 Zagreb, Croatia

Correspondence to: Dr S Oreskovic; soreskov@andrija.snz.hr

\section{REFERENCES}

1 Weber M. Basic concepts in sociology by Max Weber. (Translated and with an introduction by HP Secher.) New York: The Citadel Press, 1962.
2 World Health Organisation. The World Health Report 2000: Health systems: improving performance. Geneva: WHO, 2001.

3 Fisher ES, Welch HG. Avoiding the unintended consequences of growth in medical care: how might more be worse? JAMA 1999;281:446-53.

$4 \mathrm{http}$ ///www.dartmouthatlas.org/about.php

5 Skinner J, Wennberg JE. How much is enough? Efficiency and Medicare spending in the last six months of life. In: Cutler DM. The changing hospital industry: comparing not-for-profit and for-profit institutions.
Chicago: The University of Chicago, 2000: 169-93.

6 http://www.health.fgov.be/WHI3/krant/ krantarch2000/kranttekstmay/

$000504 \mathrm{~m} 07 \mathrm{prn} . \mathrm{htm}$

7 http://www.cptech.org/ip/health/sa/

8 Bosert T, Hsiao W, Barrera M, et al.

Transformation of ministries of health in the era of health reform: the case of Colombia. Health Policy and Planning 1998:13:59-77.

9 http://www.abc.net.au/lateline/archives/ LatelinelssuesIndex_Health.ht

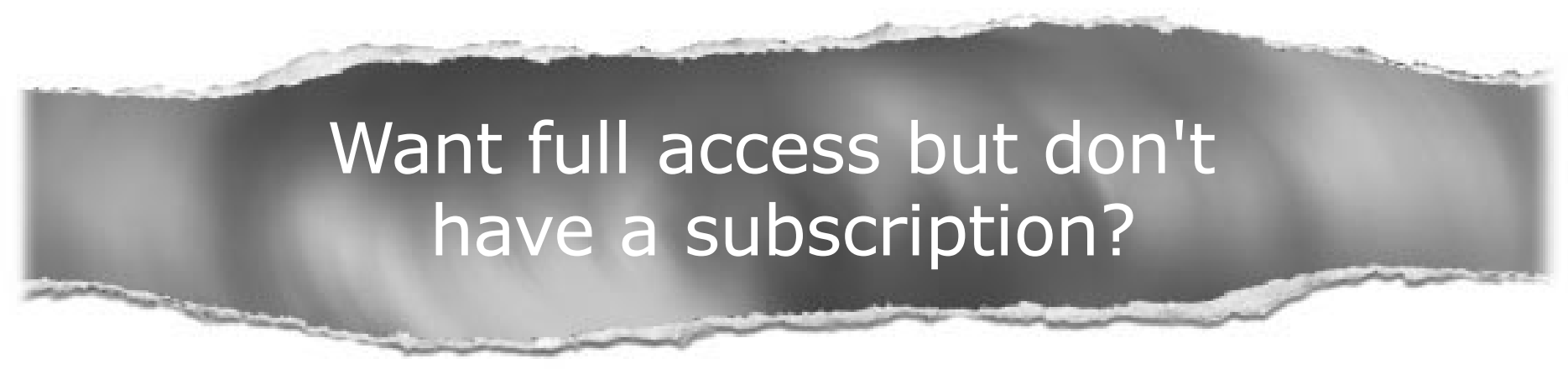

\section{Pay per access}

For just US $\$ 25$ you can have instant access to the whole website for 30 days. During this time you will be able to access the full text for all issues (including supplements) available. You will also be able to download and print any relevant pdf files for personal use, and take advantage of all the special features Journal of Epidemiology and Community Health online has to offer.

\section{www.jech.com}

